\title{
O Cotidiano das Águas no Brincar de Crianças Ribeirinhas e Quilombolas do Baixo Tocantins - PA ${ }^{1}$
}

fliana oౌojo*

\section{RESUMO}

O artigo aborda o cotidiano das águas em relação aos brincares de crianças ribeirinhas e quilombolas na região tocantina, sendo parte de uma pesquisa, em andamento, que trata das práticas educativas e culturais de povos ribeirinhos-equilombolas na Amazônia paraense. O percurso investigativo retratou dimensões culturais e ancestrais da realidade social de crianças, logo perpassou compreender suas infâncias, seus saberes; quem são e como vivem esses sujeitos. Para isso, o trabalho se reveste de uma pesquisa bibliográfica e de campo, utilizando-se de recursos etnográficos visando captar a prática social delas, tomando-as como sujeitos sociais, produtoras de conhecimento e de uma sociabilidade com seus pares e com adultos. Em consequência, foi possível perceber os processos culturais e educativos a partir do ser criança e do viver a infância em condições concretas em que os brincares e as brincadeiras; socialmente construídas se articulam, na maioria das vezes, por meio do convívio com as águas e, tais sinalizações podem ser úteis para pensar possíveis

1 O artigo abrange discussões a partir das minhas experiências de pesquisa no mesmo lócus onde se processou a tese intitulada de Gapuiar de saberes e de processos educativos e identitários na comunidade do rio Baixo Itacuruçá, Abaetetuba-PA (2017).

* Doutorado em Ciências Sociais pela Universidade Estadual de Campinas/UNICAMP. Mestra em Educação pela Universidade Metodista de São Paulo (UMESP). Professora da UFPA, Campus Universitário de Abaetetuba - PA. Licenciada em Pedagogia pela Universidade da Amazônia (UNAMA). E-mail: elianapojo@ufpa.br

@rquivo Brasileiro de Educação, Belo Horizonte, v. 6, n. 14, mai-ago, 2018. 
(re)configurações educacionais em contextos rurais na região do Baixo Tocantins/PA.

Palavras-chave: Águas. Ribeirinhos-e-Quilombolas. Crianças. Práticas educativas.

\begin{abstract}
The article addresses with the daily life of the water in relation to the jokes of riverine and quilombola children in the region of Tocantins, and it is part of an ongoing research that deals with the educational and cultural practices of riparian and quilombola peoples in the Amazon region of Pará. The investigative path portrayed cultural and ancestral dimensions of the social reality of children, and then understood their childhoods, their knowledge, who they are and how they live. For this, the study was anchored in bibliographical and field research, using ethnographic resources to capture their social practice, making them as social subjects, producers of knowledge and a sociability with their peers and with adults. As a consequence, it was possible to perceive the cultural and educational processes from the child being and living the childhood in concrete conditions in which the to play and jokes, socially constructed games are articulated, in the majority of the times, by means of the conviviality with the waters and, such signs may be useful to think of possible (re) educational configurations in rural contexts in the region of low Tocantins-PA.
\end{abstract}

Key-words: Water. Riverside and quilombola. Children. Educational practices.

\title{
1 INTRODUÇÃO
}

Para mim, quilombola é desenvolver a cultura. Assim como os nossos antepassados desenvolveram a feijoada, a maniçoba, a farinha, o tacacá e outras coisas cultivadas até hoje no meio do nosso povo(R.G.,13a, grifos

@rquivo Brasileiro de Educação, Belo Horizonte, v. 6, n. 14, mai-ago, 2018. 
meus)'. Este trecho explicativo é de uma das crianças que participou da pesquisa e, evidencia, o quanto elas são sujeitos de ideias, de interações e produtoras de cultura (BRANDÃO, 2015; KRAMER, 2007). Para Gusmão (2012, p.164), as crianças são sujeitos sociais com uma mente cultural inestimável, elas "sabem de si, sabem onde estão, o que faz parte de suas vidas; conhecem seu mundo; e se confrontam com os princípios de pertença e identidade que Ihes são atribuídos" Foi acreditando no seu potencial criativo busquei não somente a dialogar com tais sujeitos, mas substantivamente interagir com seus repertórios culturais do brincar mediados pela natureza;seus aprendizados de vida que ocorrem entre as relações escolares, relações de vizinhança e convivência com outras crianças e com adultos, cuja pesquisa situa-se em contextos diferentes da região do Baixo Tocantins, especialmente no município de Abaetetuba, visando compreenderas práticas culturais e educativas de crianças que vivem em territórios rurais (de estradas, de ramais, de matas e de águas).

No entanto, as crianças vivem suas infâncias de modo diferentes nos sistemas que cada sociedade organiza para $o$ seu atendimento e educação, como construções sociais; assim há descasos de diversas ordens quanto aos direitos delas e para elas, inclusive faço destaque aqui as muitas semelhanças de desumanização por que passam as crianças do Marajó no Pará pormenorizadas na pesquisa de Andrade e Pacheco (2016). Também, nessa região, presenciam-se situações de crianças em condições de trabalho infantil, de escalpelamento, de baixo rendimento escolar entre outras situações do tipo. Sobretudo o povo do campo historicamente tem sido desassistido quando se trata dos serviços essenciais e direitos básicos. Em suma, esse é um dado objetivo das condições existenciais de centenas de

\footnotetext{
${ }^{1}$ No decorrer do texto aparecem destacadas em itálico as 'categorias locais' em frases curtas e expressões de uso local.
}

@rquivo Brasileiro de Educação, Belo Horizonte, v. 6, n. 14, mai-ago, 2018. 
crianças do Norte do Brasil, sejam elas de contextos urbanos ou rurais, sejam de território ribeirinho, quilombola, sejam assentadas ou indígenas. Sobre esse aspecto Martins (2014) diz que elas apresentam características peculiares e, utilizando-se de depoimentos, retrata a condição fronteiriça da Amazônia, a de ser criança num espaço social que se processa por conflitos armados entre posseiros e grileiros. A fala da menina Regimar, descrita como "miúda e arrumadinha", põe em relevo o fato de a migração não se justificar apenas pela busca de terra, mas também e, simultaneamente, se justificar pela fuga da humilhação sofrida no presente. No passado e no futuro, busca-se um lugar que seja "bom para o pobre viver sua pobreza"2.

\section{ASPECTOS METODOLÓGICOS: PORMENORES DO ESPIAR ${ }^{3}$ E PRODUZIR COM AS CRIANÇAS}

Geertz (1989, p.89) defende a etnografia como uma experiência interpretativa. Nesses termos, o estudo sobre saberes e cultura local a partir das experiências de crianças em processos educativos e culturais, inscrevese de algum modo no interior de tal abordagem por pautar-se na subjetividade dos sujeitos, em meio a situações e fatos que se mostram encharcados de significados e relações. E, tomando este pressuposto a investigação teve como foco de análise o cotidiano e os aspectos culturais e ancestrais que reverberam nos brincares das crianças ribeirinhas-equilombolas de Abaetetuba-PA.

\footnotetext{
${ }^{2}$ Trata-se da obra: MARTINS, J. de S. (Org.).Regimar e seus amigos: a criança na luta pela terra e pela vida. In: MARTINS, J. de S. Fronteira: a degradação do Outro nos confins do humano. 2. ed. São Paulo: Contexto, 2014.

${ }^{3}$ Espia é um modo de falar do lugar. Com base nos usos e sentidos empregados por moradores, percebi o espiar como o apreciar as coisas nas entrelinhas, o dar atenção, o olhar à espreita, o deleitar-se no tempo sem pressa. Em analogia com os estudos de Loureiro (2015) sobre o tema, espiando vão aprendendo e ressignificando a realidade, formulam leituras de mundo já que na condição de "caboclo amazônico, na sua jornada diária, seja na caça, na pesca, nas viagens, vive a doçura obcecante do olhar". O espiar é fonte de observação (LOUREIRO, 2015, p.147).
}

@rquivo Brasileiro de Educação, Belo Horizonte, v. 6, n. 14, mai-ago, 2018. 
Como aprendiz de um modo 'artesanal' de fazer, não apenas transitei entre leituras concernentes ao tema como também por uma significativa experiência com o trabalho de campo. O percurso da pesquisa foi sendo consolidado a partir das contínuas incursões em comunidades rurais conectadas pelo fluxo natural das águas, percebendo as diversas recorrências dos brincares, suas linguagens, símbolos e simbolismos, seus brinquedos e narrativas de crianças quilombolas e ribeirinhas, com o intuito de compreender mais sobre a realidade do brincar na reinvenção e produção cultural na região do Baixo Tocantins, procurando dar visibilidade aos seus saberes, suas infâncias e seus processos interativos e educativos, os quais sinalizam outros modos de vida e, ao mesmo tempo, aprender um pouco mais do conhecimento antropológico e educacional de povos das águas.

O resultado do trabalho etnográfico na região tem ocorrido em diversas dimensões, desde trabalhos acadêmicos rápidos com acadêmicos de Pedagogia ${ }^{4}$ até a execução de projetos de pesquisa e extensão. Detidamente, os dados aqui trazidos são oriundos de imersões na região por aproximadamente três anos, ressoam a recolha de dados e de experiências formativas com crianças nas comunidades dos rios Baixo Itacuruçá e Arapapuzinho, localidades rurais de ilhas no município de Abaetetuba $^{5}$. As duas comunidades se autodefinem como quilombolas, isto é, são remanescentes de quilombos, nos termos da Constituição Federal de 1988. Porém, às proximidades há não só práticas sociais interligadas ao 'mundo

\footnotetext{
${ }^{4}$ Refiro-me a Disciplina de Fundamentos Teórico-metodológicos da Educação Infantil, a projetos de iniciação científica desenvolvidos em 2012 e 2013 e, mais recentemente à minha pesquisa de Doutorado em Ciências Sociais (2017), anteriormente mencionada.

${ }^{5}$ Somente na comunidade do rio Itacuruçá, contabilizam aproximadamente 168 na faixa etária entre zero e quatorze anos, sendo esta comunidade constituída por aproximadamente 204 famílias, contabilizando um total de aproximado de 960 pessoas entre crianças, jovens e adultos. (Fonte: Agentes Comunitárias de Saúde da comunidade, em 28/11/2016).
}

@rquivo Brasileiro de Educação, Belo Horizonte, v. 6, n. 14, mai-ago, 2018. 
das águas', como também um grande número de moradores se autodefinem como ribeirinhos. Segundo Castro (1997), o termo 'ribeirinho' na Amazônia serve para designar povos tradicionais que habitam as margens dos rios e que sobrevivem através de articulações com os recursos da terra e da mata, e com os cursos d'água. Os

[...] denominados ribeirinhos, na Amazônia, possuem uma referência, na linguagem, as imagens de mata, rios, igarapés e lagos, definindo lugares e tempos de suas vidas na relação com as concepções que construíram sobre a natureza. Os sistemas classificatórios dessas populações fazem prova do patrimônio cultural [...](CASTRO, 1997, p.226-227).

Situada a pesquisa basicamente pelo cotidiano das águas, muitas foram e ainda são as travessias. Travessias de idas a lugares cujo transporte são embarcações, rabetas e ou barcos de linha; travessias aportando em diferentes beiras e beiradas de rios, furos e igarapés para acompanhar e interagir com brincares que acontece em meio aos cursos d'água. Travessias interativas entre pessoas, adultos e crianças e, dessa forma elas foram se colocando mais à vontade nas conversas e, de certa forma, houve um misturar-se no seio do grupo social a partir das interações e diálogos.

De algum modo, colocamo-nos no remanso das águas e das crianças, observando suas infâncias na dinâmica cultural de que participam, como sujeitos que residem às margens dos rios e no convívio com a natureza.

Em 2012, quando eu desenvolvia projetos acadêmicos nas comunidades, numa breve andança pelo território, visualizei algumas crianças circulando por entre os adultos e, outras, vivenciando a ação principal da infância, o brincar. Mesmo estranhando nossa presença, vivenciavam brincadeiras e trocas entre elas no quintal, na beira do rio, nos retiros, nas pontes e na escola. Nestas primeiras incursões, a leitura de 
Fernandes (1979) foi crucial, pois vimos que as crianças dos rios Baixo, Itacuruçá e Arapauzinho transitam na rua, no caso o rio e na mata, enquanto espaços de sociabilidades e de experiências de vida. Além disso, foi impossível não perceber os gingados de seus corpos n'água e correndo entre quintais, os sorrisos e a aparente descontração, observada na área livre da escola, onde agrupavam-se crianças e adolescentes entre linhas marcadas com sandálias para, como dizem elas, brincar formô na escolab. Percebi a infância e as crianças vivenciando um cotidiano imbricado ao movimento das águas dos diversos rios que o circundam.

Partindo deste pressuposto, estar em campo demandou um espiar atento aos acontecimentos, assim como um agir no sentido de troca entre sujeitos, com especial atenção ao que elas diziam e faziam, valorizando os seus modos de vida e, principalmente suas produções culturais e educativas pelo brincar. Convivi com um grupo de quinze crianças e adolescentes entre nove e quinze anos de idade, estudantes do $4^{\circ}$ e $5^{\circ}$ anos do Ensino Fundamental, durante um ano. Todas elas moradoras das duas comunidades referidas.

Outrossim, as vivências com este grupo ocorreram por meio de 'encontros'7 e em horários diversos dos das aulas, semanalmente. Acompanhamos algumas rotinas vivenciadas nos intervalos entre a escola e a comunidade, momentos em que busquei captar as ocorrências do brincar, suas vozes sobre o rio e a mata, gapuiando 8 saberes pelo brincar.

Nesse contexto, as crianças se afirmavam crianças. Esta certificação

\footnotetext{
${ }^{6}$ Essa brincadeira consiste na demarcação do espaço onde cada integrante do grupo impede a invasão do seu espaço (quadrado) e o corpo se expressa por gingados parecidos com os da capoeira.

${ }^{7}$ Essa denominação, tal como um espaço de trocas, para Brandão (2008), configura momentos vividos, onde o "aprender significa abrir-se ao fluxo impermanente e inesgotável do saber. Aprender é um encontro. É um sempre ir-ao-encontro-de" (BRANDÃO; BORGES, 2008, p.19, grifos meus).

${ }^{8}$ Derivação de gapuia. Logo, gapuiar, é um tipo de pesca no igarapé ou furo. Significa retirar a água de poços que se formam nos igarapés (olho d'água) durante a maré seca, para, deles, apanhar o peixe e/ou o camarão aprisionados (grifos meus).
}

@rquivo Brasileiro de Educação, Belo Horizonte, v. 6, n. 14, mai-ago, 2018. 
veio a partir do posicionamento de dois meninos, os de mais idade; eles não só pediam para brincar, como também narravam os seus brincares espontaneamente. Em campo, muitas vezes, presenciei esses meninos e, em muitas ocasiões, meninas e meninos maiores de treze anos juntos de crianças menores envolvidos com algum fazer, inclusive o de brincar. Além disso, chamou minha atenção a fala de uma moradora. Ela, capinando a roça ao lado da escola, observava adolescentes que se movimentavam em frente da instituição e, comentou: tem umas que já namoram e brincam fio, pulam corda. O brincar não tem idade. Tais afirmações evidenciam que a brincadeira e a ludicidade na comunidade são vistas como ações do cotidiano exercidas por grupos infantis e com valorização dos adultos.

Em meio a tudo isso a travessia metodológica das vivências incluiu conversas informais e entrevistas em grupo; sessões de brincadeiras, visitas aos espaços, caminhadas na mata, discussões com base em alguns temas, buscando, como já mencionei captar o universo dos saberes locais pela produção do brincar por crianças quilombolas e ribeirinhas. Em síntese, o trabalho de campo envolveu alguns procedimentos, tais como:

a) observação participante sobre a vida social e sócio produtiva, e em diversos outros momentos do cotidiano das comunidades. Aqui interagi com moradores do lugar e, especialmente, com as crianças, por meio de conversas informais e andanças nos lugares com elas, auxiliando o registro etnográfico sobre a vida local.

b) conversas informais e entrevistas com docentes, gestores e responsáveis de crianças buscando retratar os brincares, as manifestações culturais e condicionantes sociais das comunidades?.

\footnotetext{
${ }^{9}$ No caso dos adultos envolvidos com a pesquisa, houve consenso e consentimento para declaração de seus nomes.
}

@rquivo Brasileiro de Educação, Belo Horizonte, v. 6, n. 14, mai-ago, 2018. 
c) elaboração de esquemas e de croquis de alguns espaços sociais e das brincadeiras que se relacionam com a geografia das águas com os furos e os igarapés do entorno e a paisagem natural do território, produzido por crianças e adolescentes ${ }^{10}$ durante as vivências de campo e oficinas.

d) sistematização e análise dos dados e informações obtidos no estudo, articulando a recolha de dados com a realização da pesquisa bibliográfica e de campo, considerando o contexto sociocultural Amazônia Paraense.

No percurso dos encontros, presenciei olhares, cochichos, aproximações, descontrações, constituindo os dados para a análise e para a produção do conhecimento, considerando as crianças como sujeitos sociais. Muitos lugares e andanças foram indicados pelas próprias crianças, emitidos por suas falas e seus relatos, por desenhos e por brincadeiras, por fotos e por vídeos produzidos conjuntamente.

\section{POR UMA 'GEOGRAFIA DAS ÁGUAS'}

Este item busca situar a Amazônia paraense e, em particular, a região tocantina, em seus contrastes dada sua riqueza humana e, sua diversidade sociocultural e territorial em meio aos diversos dilemas socioeconômicos vividos pelos habitantes de territórios rurais e urbanos. Também, se introduz o que ouso chamar de "geografia das águas" em contextos de ilhas nessa região, a qual transversaliza ambientes naturais, as moradias, o ciclo comercial e, principalmente o cotidiano sociocultural e produtivo das pessoas.

10 Sobre o ciclo de vida de crianças e adolescentes e o como identificá-las, Brandão (2015), nomeia-as de criança-adolescente, de criança-estudante e de pessoa-estudante.

@rquivo Brasileiro de Educação, Belo Horizonte, v. 6, n. 14, mai-ago, 2018. 


\subsection{Amazônia e Amazônia Paraense 11}

Nosso país concentra a maior parcela da principal floresta tropical do mundo, a Amazônia 12. No dizer de Maués (1999), constituem-se na realidade muitas Amazônias, de muitas visões; algumas delas, até contestadas e outras, em construção, considerando os aspectos econômicos, geográficos e sociais ${ }^{13}$. O certo é que a realidade amazônica é diversa, dada sua rica biodiversidade, suas etnias e suas diferentes culturas.

Nesse vasto contexto amazônico, o Pará é o segundo Estado em extensão territorial, em que a floresta ou a mata ${ }^{14}$, situa-se por um contexto de gentes, de paisagens, de saberes-fazeres, de memórias e muitas histórias.

Esta Amazônia paraense é composta de cidades urbanas e rurais, que possuem interconexões com o simbolismo amazônico dado suas matas ou florestas, suas extensas áreas de várzea e, ainda a temporalidade das águas emanando toda uma dinamicidade social de vida cabocla. Ou, tomando a impressão de Euclides da Cunha (1999) trata-se de um "excesso de águas" que circunda a vida dos caboclos da Amazônia. Ela concentra em si todo um conjunto de fatos e condicionantes socioeconômicos reveladores diante da construção de alteridades e de conflitos sociais, de confrontos entre comunidades tradicionais e empresas 15 , de disputas a partir dos

\footnotetext{
${ }^{11}$ Trata-se de um modo próprio de identificá-la que foi formulado no conjunto de ações e discussões dos movimentos e agentes sociais do campo, para distinguir a área territorial com suas paisagens, florestas, terras e águas na Amazônia do Pará.

${ }^{12}$ São várias caracterizações sobre a Amazônia, datada por âncoras histórica e cronológica. Sobre o assunto, ler Castro (2000) e Maués (1999). Refiro-me aqui a região amazônica adotamos o conceito clássico referindo-se ao território que abarca os Estados do Acre, Amazonas, Amapá, Pará, Rondônia e Roraima; diferentemente da denominação de Amazônia Legal.

${ }^{13}$ Cito dois olhares: a da Amazônia fronteiriça, em que diferentes atores estão em permanente situação de conflito social (MARTINS, 2014) e a da valorização da diversidade cultural, associada à autodefinição dos agentes sociais e à sua condição de sujeitos (ALMEIDA, ; FARIAS, 2013).

${ }^{14}$ Termo utilizado para referir-se a floresta por muitos habitantes de áreas rurais da região.

${ }^{15}$ Exemplo típico, na Amazônia paraense, é o caso da massificação da dendeicultura na região do Baixo Tocantins (NAHUM; SANTOS, 2013).
}

@rquivo Brasileiro de Educação, Belo Horizonte, v. 6, n. 14, mai-ago, 2018. 
posicionamentos do Estado e os dos movimentos sociais e, assim por diante. $E$, no que tange aos contextos rurais, são vários os elementos que configuram situações fronteiriças em diversas dimensões como a da produção agrícola, da luta pela terra, da sustentabilidade social mediada pelo uso dos recursos naturais, a do fechamento de escolas etc.; as quais são parte das experiências de povos ribeirinhos, quilombolas, extrativistas, atingidos por barragens, assentados entre tantas outras especificações. Significa dizer que no Pará a Amazônia se constitui tanto com uma natureza esteticamente bela quanto com o fenômeno da precarização da vida e da exclusão socioeducacional que aflige historicamente os povos do campo e das cidades nessa região.

\subsection{Situando a Região do Baixo Tocantins}

O cotidiano das águas da microrregião de Cametá, mais conhecida como Baixo Tocantins, é entrecortado pelos rios Moju, Pará e o Tocantins. A região é uma das áreas de colonização mais antiga tal como a Bragantina e, as duas, estão inseridas no que identificamos como mesorregião Nordeste paraense. São vários os municípios que a compõem, cito: Acará, Abaetetuba, Barcarena, Cametá, Igarapé-Miri, Limoeiro do Ajuru, Oeiras do Pará, Baião, Mocajuba, Moju e Tailândia.

Viver nesta região significa conviver, bem mais do que em outros territórios e cenários, com a tríade fundamental à vida: a terra, as águas e as matas através de uma cultura própria, ou de diversas culturas refletidas no cotidiano dos amazônidas. E, pontualmente concentra em si uma geografia das águas, notadamente pelo trançado de seus rios, furos, igarapés, suas praias estacionadas, as marés intermitentes, além do rotineiro trânsito fluvial

@rquivo Brasileiro de Educação, Belo Horizonte, v. 6, n. 14, mai-ago, 2018. 
dando fluidez a sua complexidade e amplidão regional.

As águas dos rios e adjacentes se misturam à vida das pessoas. O rio é mar, se dispondo em extensões territoriais para ribeirinhos equilombolas, o riomardistancia e aproxima gentes e contextos. Os "excessos de águas" são úteis à alimentação, ao trabalho, ao lazer e aos brincares das crianças, adevaneios poéticos e histórias lendárias. Imbricados ao movimento das águas transcorre saberes e tradições, transcorre o homem e o rio, transcorre por vezes a vida e por outras, a morte. Nessa região marcada pela realidade desse estuário, pode-se contara oscilação de horas em que as águas dos rios, furos e igarapés condicionam a vida do povo. Um pôr do sol sob o reflexo das águas é um momento ímpar, que pode ser observado com frequência por professores que trabalham em escolas do campo e, realizam, travessias cotidianamente às ilhas. Para as crianças o rio é grande em extensão e, o igarapé, é pequeno.

Nos territórios dessa região há indígenas, brancos, negros e mestiços. Os nativos e os chegantes em busca de melhores condições de vida, como os nordestinos e outros que vieram de terras mais distantes, caso de europeus. As comunidades quase sempre se situam em "terras de marinha"16, outras em fazendas, outras em área quilombola etc. Geralmente são áreas denominadas como terra firme, várzea ou de ilhas.

\subsection{0 'mundo das águas' em Abaetetuba e nas comunidades}

A partir do contexto das comunidades onde foi realizada a pesquisa, de agora em diante a ênfase é situar o cenário social e geográfico das águas, trazendo um pouco da prática social exercida no lugar de modo

\footnotetext{
${ }^{16}$ Moram os ditos ribeirinhos, habitantes de Terras de Marinha, como bens da União.
}

@rquivo Brasileiro de Educação, Belo Horizonte, v. 6, n. 14, mai-ago, 2018. 
geral e, também, aspectos do cotidiano das crianças em suas relações de convívios, sociabilidades e menos do processo de escolarização, os quais passam pela compreensão do desenvolvimento do homem e da mulher amazônidas.

Abaetetuba localiza-se na região mencionada e, ocupa uma área de $1.610,75 \mathrm{Km}^{2}$, cuja área é cercada de ilhas formando uma complexa geografia de águas.Situa-se pelo estuário dos rios Pará e Tocantins, rios esses que formam a baía de Marapatá nessa região. Possui uma população de aproximadamente 142 mil habitantes, sendo que 45 mil habitantes do total vivem na região das ilhas.

Em termos gerais, as comunidades quilombolas e ribeirinhas de Abaetetuba, como comunidades tradicionais situam-se em ilhas; e outras, nas estradas e nos ramais. Trata-se de um município constituído de muitos rios e de matas, com características campesinas que comportam uma pluralidade de ribeirinhos, pescadores, colonos, assentados, peconheiros ${ }^{17}$, quilombolas etc.; eminentemente agricultores de hortaliças, do intenso cultivo do açaí e da mandioca, da produção da farinha, da criação de animais, do artesanato, da carpintaria, da pesca e, agora, com força, de trabalhadores das empresas que estão atuando no monocultivo do dendê. Os moradores do campo possuem "[...] saberes e práticas sobre os variados ecossistemas, fato que Ihes confere conhecimento e habilidades diversas e plurais acerca do complexo roça-mata-rio-igarapé-quintal" (OLIVEIRA, 2008, p.37).

Os territórios dessa região assentam-se em particularidades e interconexões geográficas, políticas, econômicas e culturais expressas por relações sociais, institucionais e a partir da convivência das pessoas e destas

\footnotetext{
17 Atuam na apanhação do açaí. E, a peconha é o instrumento de subir no açaizeiro e coletar o fruto, produzida com a folha da palmeira.
}

@rquivo Brasileiro de Educação, Belo Horizonte, v. 6, n. 14, mai-ago, 2018. 
com o ambiente.

As águas e as embarcações formam na beira um ritual à parte. Esse movimento com as pessoas dá viveza ao cotidiano do município e, também, à comunidade do rio Itacuruçá. Constituem os rios e as águas espaços da ação do sujeito amazônico, em que as águas abundam e fundam o ethos ${ }^{18}$ do quilombola, do habitante de ilha, do ribeirinho, do caboco, do embarcado.

Em grande parte de Abaetetuba, o rio é a rua, com nomes oriundos da sabedoria indígena, sendo o principal rio o Pará, fora os outros, que também são importantes para a vida social e econômica do lugar. Os inúmeros rios, igarapés e furos diferenciam o município em razão da dinamicidade das suas águas. Na cidade, há setenta e duas ilhas, além das trinta e cinco 'colônias' (ramais e estradas) e dos dezessete bairros na área urbana. Grande parte das ilhas é habitada.

A beira ${ }^{19}$ da cidade, também chamada de trapiche, de porto tem um papel indiscutível na vida dos abaetetubenses, é o lugar de encontro onde são resolvidos, ou não, os negócios: a transação comercial, a encomenda que vai para outro destino, o embarque para cuidar da saúde entre outras situações, antes das diferentes embarcações saírem para tantas responsabilidades. É lá, na beira, que ficam ancorados, desde cedo: a canoa a remo, a montaria, o casco, o batelão, a bajara, o barco à vela, a rabeta e o rabudo, as quais apresentam cunhadas em suas laterais ou pintadas em suas paredes informações indicando a velocidade do percurso, o preço da passagem e o nome do dono. Atualmente a mais cogitada dessas embarcações é a conhecida rabeta, embarcação própria da

\footnotetext{
${ }^{18}$ Nos termos do antropólogo Clifford Geertz (1989).

19 Esta expressão se refere ao berço da colonização do município de Abaetetuba, conhecida como feira, onde são comercializados a produção agrícola, pesqueira, artesanal, extrativista, entre outros produtos manufaturados.
}

@rquivo Brasileiro de Educação, Belo Horizonte, v. 6, n. 14, mai-ago, 2018. 
maioria dos moradores, é de fácil manuseio, ágil e de valor acessível.

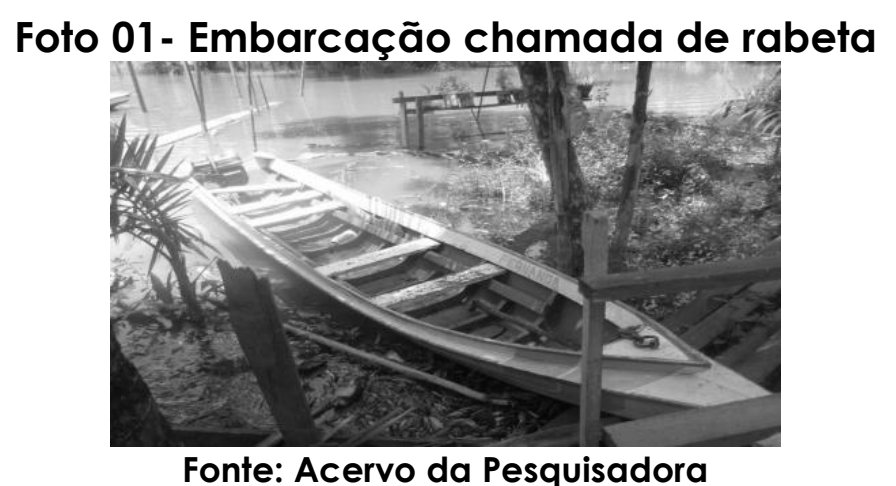

Para os moradores de ilhas, o tempo da natureza, os rios e igarapés são responsáveis pelos seus destinos e pelo seu cotidiano. Há uma intimidade entre o homem e o território ribeirinho. "Por via prazerosa, o homem da Amazônia percorre pacientemente as inúmeras curvas dos rios, ultrapassando a solidão de suas várzeas [...]" (LOUREIRO, 2015).

O cotidiano do povo ribeirinho em seu movimento de ir e vir entre as águas dos rios vai dando materialidade ao território ilhéu sedimentando sua rica diversidade cultural, numa simbiose em que o homem e as águas sedimentam um ciclo de uma mesma geografia humana e das águas em Abaetetuba.

Nesse sentido, a cultura dos povos rurais, de ribeirinhos e quilombolas vão se modelando e nada mais é do que o produto das ações e das simbologias que as comunidades vão construindo no seu existir. As experiências de trabalho na coleta do açaí, os ciclos das marés que favorecem ou não a pesca, os fenômenos climáticos, a fabricação e uso de utensílios usos na pesca ou na colheita do açaí, os riscos que vivenciam navegando em canoas pequenas pelos rios são as várias estratégias de que os moradores se valem para viver o contexto ribeirinho, dialogar com o mundo e ensinar às crianças, pela vivência, como se vive num mundo cuja

@rquivo Brasileiro de Educação, Belo Horizonte, v. 6, n. 14, mai-ago, 2018. 
constituição geográfica compõe-se de inúmeros rios e de terra limitada pelas águas; cuja idealização e a realidade se conectam com a insularidade amazônica.

O mundo das águas de ribeirinhos e quilombolas movimenta a urbise a urbisse oxigena da amazôniágua das ilhas e, ambas produzem-se mutuamente. E, parte integrante da sociodiversidade, encontra-se uma rica arena mítica cabocla, traduzida, por vezes, no culto pelo encantado (causos, assombrações e mitos), ao que encanta (manifestações e paisagens) e ao encantamento (acolhimento aos que chegam) ${ }^{20}$. Também, estão presentes nessa arena mítica cabocla, a antiga tradição de contar histórias e da transmissão oral. Assim, as pessoas do lugar sugerem diferentes visões de mundo permeadas por mitos, lendas, religiosidade que povoam o imaginário e o simbolismo dos sujeitos e, no caso "[...] do fundo do rio emergirá uma nova Abaetetuba, sem dor e sofrimento, cheia de paz, amor e prosperidade [...]" (MACHADO, 2008, p.67).

O contexto ribeirinho e quilombola onde ocorreu a pesquisa situa-se, no rio Itacuruçá. É um rio comprido, forma um conjunto paisagístico com áreas de terra firme, de várzea, de matas ${ }^{21}$ e também com faixas de areia. Partindo de Abaetetuba (da beira), leva-se em torno de trinta minutos a uma hora até a comunidade, em um percurso por águas 22 .

Machado (2005), em seu livro "Glossário abaeteense: palavras e expressões do linguajar regional", faz menção aos termos: furo como

\footnotetext{
${ }^{20}$ Para o aprofundamento do tema e correlatos a obra de Loureiro (2015): "Cultura Amazônica: uma poética do imaginário". Nela, o autor enfatiza a existência de uma cultura amazônica construída entre os elementos mágicos, místicos e da natureza afirmando a partir disso que os diferentes povos amazônicos possuem uma cultura que se apresenta de forma diferenciada das outras regiões que compõem o Brasil.

${ }^{21}$ Denominação utilizada pelos moradores, ao contrário do usual, floresta.

${ }^{22} \mathrm{~A}$ variação é devido à maré e ao tipo de embarcação. Na comunidade existem pelo menos sete embarcações ou barcos de linha (freteiros) que realizam viagens, saindo do rio entre $04 \mathrm{~h}$ até 06 horas e retornando às $11 \mathrm{~h}$ da beira no valor de $\mathrm{R} \$ 5,00$. Ressalta-se que também, é possível chegar à comunidade e dela sair pela rodovia PA 151, na altura do Km 16, antes de chegar ao município de Igarapé Miri, percorrendo o ramal Itacuruçá ou Santa Rosa.
}

@rquivo Brasileiro de Educação, Belo Horizonte, v. 6, n. 14, mai-ago, 2018. 
"pequeno canal estreito de um rio que contorna uma ilha e, adiante, reencontra-se com o mesmo rio". Igarapé: "Pequeno rio. É palavra tupi que, literalmente, significa 'caminho de canoa'" (MACHADO, 2005, p.17-18).

Com base nas travessias realizadas, é possível afirmar que o rio é também cenário de interações positivas entre os moradores, pelo que lhes é comum, daí situar o beira do rio. Por ele, é possível perceber certo cotidiano acontecendo: crianças escovando os dentes e mães lavando roupas na cabeça das pontes; embarcações fazendo a travessia até a cidade; pessoas à beira da ponte acompanhando o movimento das embarcações. Ao entardecer nos trapiches, pessoas põem-se a iscar23 o matapi para a pesca do camarão. O rio se manifesta como uma espécie de linguagem da vida amazônica.

Nas comunidades do rio Itacuruçá, os rios margeiam temporalidades. É costumeiro ouvir das pessoas do lugar: a gente foi criado n'água por configurar-se como um sinalizador da vida. São tão fortes na vida da comunidade que é pelo nome deles que a escola e a comunidade quase sempre são identificadas, ou seja, os nomes pelos quais a comunidade se orienta, se identifica, se conhece e reconhece é pelo nome do rio. Seu Dilo afirmava que para uma pessoa viver às margens das águas é preciso aprender todas as manobras dele: as pedras, as marés, a remar24. 0 morador denota um conhecimento local, talvez indecifrável para quem não interagiu com esse contexto, retratando acerca desse ser criado n'água, que trata de um mapa do lugar na cabeça e, que diz muito como é fazer comunidade e da construção social pelas pessoas pautada no dia a dia das pessoas.

${ }^{23}$ É o preparo do matapi para a pesca do camarão.

${ }^{24}$ Fragmento de Raimundo Dilo de Couto, 87 anos - in memoriam. Um dos moradores mais velhos, fora citado e reconhecido por outros como uma espécie de arquivo vivo da história do lugar e um militante da questão quilombola.

@rquivo Brasileiro de Educação, Belo Horizonte, v. 6, n. 14, mai-ago, 2018. 
O mover-se das pessoas e embarcações consubstancia uma dinâmica social, que dependendo do período, verão ou inverno 25 , altera a sua rotina. Nesse sentido, o rio e os demais lugares de furos e igarapés, posicionam-se como território e fronteira; devido sua expressão cultural, por constituir-se num espaço dinâmico e de interatividade, em que se processam ricas experiências étnicas, de classe, de valores, de vizinhança, de ciclos de trabalho e de relações sociais. Nos termos de Martins (2014), o rio e a terra, marcam uma condição fronteiriça geradora de alteridades e, também, de conflitos. À guisa de exemplo, as corridas de embarcações velozes praticadas por jovens, as quais terminam em confusão durante os fins de semana. Ou, ainda, pessoas de fora chegam para pescar gerando desentendimentos.

O rio participa de tudo, observado por muitos como produtor e, hoje, percebem como consumidor das coisas que são vendidas às suas margens. Os rios, os furos e os igarapés, que delimitam e contornam a área da comunidade, possuem diferenças e formas de usos também diferenciados, pois de certa forma existe hierarquia entre eles ${ }^{26}$. O rio é maior, fazendo com que haja um movimento contínuo de embarcações e pessoas, assim como a circulação de informações. A parte do Baixo é a mais larga e por onde se dá o acesso principal, mas sua nascente está no Alto do rio. Na parte do Baixo, as marés permanecem por mais tempo, permitindo o trânsito em toda sua extensão, a exceção é a llhinha. Já os furos e os igarapés são mais restritos

\footnotetext{
${ }^{25}$ Certamente que as denominações das estações climáticas são produzidas culturalmente, por isso indicar verão e inverno amazônicos em suas peculiaridades. Os quilombolas vivenciam uma mobilidade territorial de acordo com as duas épocas: chuvas intensas e o período de verão. $\mathrm{Na}$ primeira, eles ficam mais em casa, caracterizando, grosso modo, pela utilização dos recursos adquiridos durante o período do verão como a lenha e a farinha, assim como diminuem consideravelmente as atividades de agricultura e o processamento da farinha. $O$ verão é de trabalho intenso de colheita do açaí, da produção das olarias, da agricultura, da produção do carvão e da lenha.

${ }^{26}$ Sobre o assunto, consultar os estudos de Rezende (2016).
}

@rquivo Brasileiro de Educação, Belo Horizonte, v. 6, n. 14, mai-ago, 2018. 
em uso, devido ao fluxo das águas e, ainda, por possuir um quantitativo pequeno de pessoas que moram lá.

Ocorre que o rio em toda sua extensão, abarca muitos ambientes e foram os próprios moradores locais que dividiram as áreas para se localizarem, conforme discriminado:

Baixo: corresponde a porção do curso do rio com residências, olarias, o centro comunitário e a capela da igreja católica, o ramal Santo André, entre outros. Faz limite com os rios Arapapu, Arapapuzinho e Ipanema; com os furos do Gaita, São Pedro, Filhote, Filhotinho, Sacaizal, Andreza e Cuteua; com os igarapés: Aricuru, Patauá e Porão. O findo da área é delimitado pela ilhinha e a igreja evangélica. Ainda, a área do Baixo faz limite territorial com o sítio Oiapoque (Arapapauzinho) e com o campo da natureza (área de preservação). Na entrada do rio é que se põe, segundo os próprios moradores da redondeza, a dificuldade de definir uma parte da área: se ribeirinha ou quilombola.

Médio: curso do rio com casas nas margens direita e esquerda e olarias de ambos os lados. Os quilombolas delimitam como marco inicial a casa do seu Pinto, próxima ao igarapé São João e o limite fim, a casa do Preto. Lá se encontram a Escola Raimundo Bandeira, a igreja católica e o ramal São João, de onde saem ônibus diariamente até a cidade. O nome da comunidade é o nome do igarapé (São João) e a santa padroeira é Nossa Senhora do Pau Podre.

Alto: inicia no meio do São João e encerra no fim do rio, na cabeceira. Há o ramal da Brasília. Lá se concentram a produção mais intensa da farinha e das roças; a produção de montarias e outras embarcações, além da produção de carvão e de lenha. Nomeiam-na de comunidade Nazaré, nome da santa padroeira. Essa parte é apontada pelos quilombolas como o

@rquivo Brasileiro de Educação, Belo Horizonte, v. 6, n. 14, mai-ago, 2018. 
lugar primário de refúgio dos negros.

Tanto as famílias e os conhecidos que vivem em toda extensão do rio, assim como as comunidades próximas, tanto as da área de terra firme quanto as de várzea, tanto ribeirinhos ou quilombolas correlacionam-se com os recursos naturais, visto que potencializam serviços e produtos, viagens e percursos, sociabilidades e aprendizados.

Ao apurar as informações coletados durante o trabalho de campo, ficou nítida a diversificação das atividades e um complexo intercâmbio de relações sociais e comerciais entre as comunidades próximas. A exemplo, a comunidade do Arapapuzinho possui comunicação por terra através dos caminhos e dos ramais. Inclusive, o acesso pela terra e pelos rios tem aumentado gradativamente nas comunidades quilombolas e ribeirinhas. As relações se dão nos campos do parentesco, da religião, da convivência entre vizinhos, de parcerias de trabalho, em transações comerciais simples através de produtos como a farinha e o açaí. Também, dão-se por meio das lutas nas instituições: escola e organizações sociais.

A denominação terra firme, tal como empregada pelos mais antigos, assume vários sentidos. Na terra firme, discriminam de centro para a área das roças, para os diversos caminhos e os retiros e de mata adentro para área de floresta, onde concentra-se a rica diversidade de espécies da fauna e da flora.Na terra firme, ficam os locais distantes da beira do rio ou o lá em terra, como por exemplo, o campo de futebol, o ramal ou os retiros. Nela, além especificar os lugares do agir cotidiano, referem-se, também, ao lugar afastado e que exige cuidado redobrado, devido afirmarem ter o risco com situações e com pessoas estranhas, vindas de fora.

O "povo do campo", em sua sabedoria, costuma dizer: nesse lugar criei meus filhos e tiro meu sustento; nessa terra tudo dá, mas muitos não querem

@rquivo Brasileiro de Educação, Belo Horizonte, v. 6, n. 14, mai-ago, 2018. 
mais essa prática. Esses são fragmentos repetidos por moradores e estão imbuídos de valoração e não somente ao seu uso. As crianças brincam e aprendem às primeiras lições do mundo camponês, elas reconhecem as plantações dos terreiros das casas, apanham frutas, circulam nos caminhos entre a vizinhança. Subjaz práticas do comer, do comunicar, do trabalhar, do emprestar/emprestar-se na precisão e é canal e transmissor de saberes. As pessoas não consideram apenas seu aspecto físico, ao contrário, ela a terra, é espaço das muitas práticas sociais do viver. Alguns estudos, como o de Gusmão (1991), apontam que

\begin{abstract}
A terra é um patrimônio comum das comunidades que a tomam como tal em razão de fatores étnicos, da lógica endogâmica, casamento preferencial, regras de sucessão, e outras disposições. A condição de posse comunal e indivisa é o ponto central para sua compreensão. Investida pela história própria, torna-se um território e sobre ele, os grupos negros constroem sua territorialidade (GUSMÃO, 1991, p.31).
\end{abstract}

Ou seja, a terra manifesta-se como campo fértil do processo identitário daquele grupo quilombola e, também de ribeirinhos.

Pela mata, processam-se fazeres do tipo: retiram a lenha para produção de carvão; caçam; apanham açaí dos açaizeiros sem dono; caminham entre a vizinhança e as localidades próximas, retiram as poucas madeiras existentes.

A varja é a área representada por diferentes espaços como a cabeça da ponte, a boca do rio, a cabeceira da ponte, a beira do rio, o trapiche, além de situar os furos e os igarapés. Por exemplo, quando dizem: lá na cabeceira, estão se referindo à parte do Alto Itacuruçá, ou, ainda, quando dizem: deixa eu ir na beira, comprar comida, referem-se à cabeça da ponte da casa ou o trapiche da escola.

Na cabeça das pontes, nos trapiches, nos caminhos, nos rios, nos retiros,

@rquivo Brasileiro de Educação, Belo Horizonte, v. 6, n. 14, mai-ago, 2018. 
nas roças e nos quintais, as pessoas não só compartilham o espaço físico, como também interagem mutuamente. Nesses espaços partilhados por grupos familiares, os adultos, os jovens e as crianças, através das atividades rotineiras ou de algum entretenimento, utilizam e circulam por eles. Pelas pontes, por exemplo, andam de uma casa para outra; de um local para o outro, vivenciando as trocas, os pedidos, os empréstimos, as informações. Em síntese, vivenciam formas de dar, de receber e de retribuir, de serem solidários uns com os outros (MAUSS, 2013). Outros lugares como as igrejas, as olarias, as tabernas, o barracão e o ramal Santo André promovem outras interações. Decorre que o lugar abarca outros ambientes. Estar na beirada, em um caminho, no campinho ou numa vila de casas, também pode significar estar no Itacuruçá Baixo.

Dentro desta dinamicidade territorial encontra-se o cotidiano e a sociabilidade das crianças que habitam em tais comunidades. Elas estão presentes em contextos diversificados como nas escolas, nos locais de trabalho, nos quintais, nas pontes e trapiches de suas casas.

\section{O REMANSO DAS ÁGUAS NO BRINCAR DE CRIANÇAS QUILOMBOLAS E RIBEIRINHAS}

Como parte substancial desse escrito, a ideia aqui é descrever e caracterizar o aprendizado de crianças em seus processos educativos e culturais, com vistas a compreender como elas participam da vida eminentemente mediado pelo brincar e, dessa forma apreendem, inventam e reinventam saberes e significados do universo amazôniágua-e-camponês a partir dessas relações.

Sabemos que o brinquedo e o brincar são vistos enquanto movimento

@rquivo Brasileiro de Educação, Belo Horizonte, v. 6, n. 14, mai-ago, 2018. 
de libertação da criança, na medida em que possibilitam por esse fazer e instrumento reinventar seu mundo, ao mesmo tempo, que constroem e reproduzem uma vida social. Na visão de Benjamin (1984, p. 14) os pequenos constroem seu mundo de coisas, sua própria cultura. Assim, elas "[...] fazem história a partir do lixo da história [...]"e se aproximam dos "inúteis", dos "inadaptados" e dos marginalizados, como declara o autor.

No caso de povos nesse pedaço da Amazônia, a água está presente na formação da identidade nativa. As crianças aprendem a se equilibrar no trapiche de suas casas, a brincar dentro da canoa, a tomar banho diário no rio e/ou na chuva, a lidar com a enchente e a vazante das marés, com o friozinho que vem lá do rio entrando pelas frestas das paredes das casas. As imagens abaixo expressam bem a imbricação da água na constituição formativa das crianças, no seu saber, no seu lazer, na sua relação com a natureza porque estabelecem, precocemente, uma intimidade com rio-mar.

\section{Fotos 02 e 03 - Crianças brincando com a maré seca e tomando banho no rio Baixo Itacuruçá-Abaetetuba}
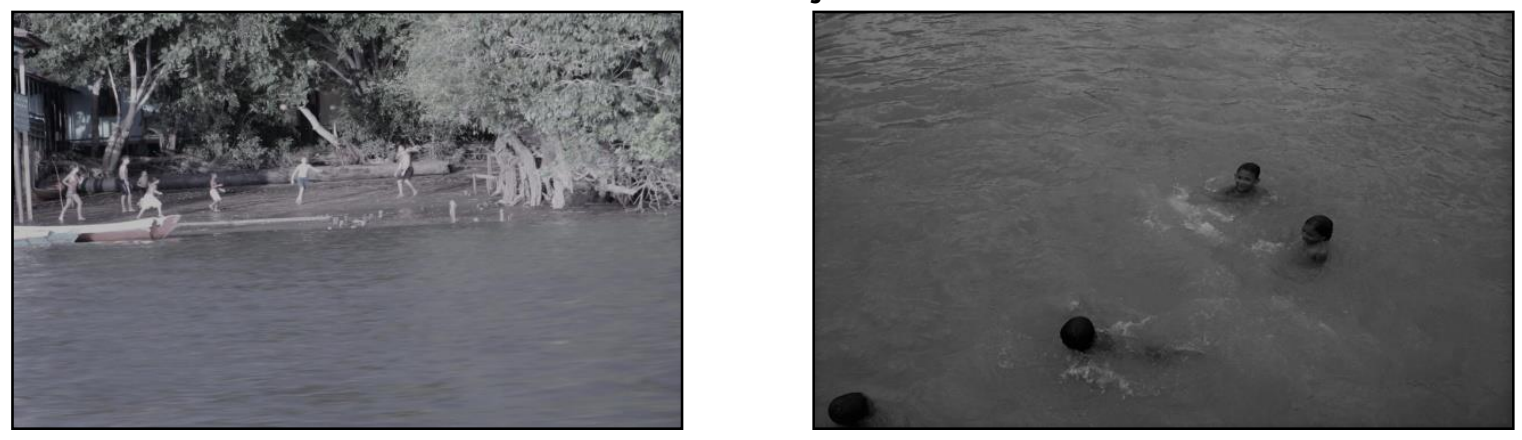

Fonte: Acervo da Pesquisadora

De um modo geral, no rio, adultos e crianças banham-se e brincam, demonstrando que por meio de atividades rotineiras ou de algum entretenimento, utilizam esses espaços ou circulam entre eles. As crianças conversam sentadas nas pontes que unem as casas e, por estas pontes ou

@rquivo Brasileiro de Educação, Belo Horizonte, v. 6, n. 14, mai-ago, 2018. 
trapiches caminham de uma casa para outra; de um local para o outro e, assim vivenciam as trocas, os pedidos, os empréstimos e as informações. Os lugares-territórios que estão atravessados por saberes e fazeres, são partes da vivência da criança quilombola/ribeirinha. Nessa perspectiva Pojo (2017, p.143) considera que:

O rio é a rua. O quintal, a mata, os caminhos, as pontes e as águas são espaços de interlocução nas vivências de uma geração que ainda brinca de nadar no rio, de subir na árvore, de pular da ponte no rio, [...]. E pelo brincar, traduzem, afirmam e recriam formas culturais por meio da linguagem, aliás, expressam pela oralidade todo o conhecimento e sabedoria que aprendem desde cedo no cotidiano beira rio. (POJO, 2017, p. 143)

Partindo desta visão sobre o território com 'coisas, memórias e costumes representando a cultura, o brincar no rio e na mata representam, também, desenvolver a cultura, pois por meio de seus brincares elas apreendem e interpretam o contexto vivido, o convívio com as pessoas e com a natureza. Aprendem através de gestos, de atos, de crenças, de causos, de gramáticas sociais e de suas linguagens, demarcando territórios naturais, sociais e simbólicos. Territórios que influenciam e que são influenciados pela cultura.

Os locais onde as crianças brincam são espaços do território que elas transitam cotidianamente e estão empapados de significações identitárias, históricas, ambientais e de raízes ancestrais do grupo, pelos quais elas vão intermediando a dimensão individual de suas vidas com o tornar-se um 'ser social' e, dessa forma, vão incorporando modos próprios de espiar, de sentir e de agir que elas não aprenderiam espontaneamente. Agem assim culturalmente e na cultura, como afirma Brougère (2000, p.76):

A brincadeira é, antes de tudo, uma confrontação com a cultura. $\mathrm{Na}$

@rquivo Brasileiro de Educação, Belo Horizonte, v. 6, n. 14, mai-ago, 2018. 
brincadeira, a criança se relaciona com conteúdos culturais que ela reproduz e transforma, dos quais ela se apropria e lhes dá uma significação. A brincadeira é a entrada na cultura, numa cultura particular, tal como ela existe num dado momento, mas com todo seu peso histórico. A criança se apodera do universo que a rodeia para harmonizá-lo com sua própria dinâmica. Isso se faz num quadro específico, por meio de uma atividade conduzida pela iniciativa da criança, quer dizer, uma atividade que ela domina, e reproduz em função do interesse e do prazer que extrai dela. A apropriação do mundo exterior passa por transformações, por modificações, por adaptações, para se transformar numa brincadeira: é a liberdade de iniciativa e de desdobramento daquele que brinca, sem a qual não existe a verdadeira brincadeira.

Vemos que o brincar constitui-se em uma aparente espontaneidade como uma tarefa obrigatória, diária e franca é ativamente socializadora. Brinca com o irmão, com o amigo, com o primo. Ao perguntar para M.G. sobre com quem aprendeu as brincadeiras que sabe, ele me disse: [...] espiando os outros brincarem, brincando [...] com outras pessoas (pai e tios) e outras crianças. E, algumas brincadeiras são intensamente construtivas. São frequentes nos terreiros, as casinhas feitas com folhagens, pedras e galhos. As crianças brincam por entre as casas ou sentadas na terra. Nas árvores, elas amarram pedaços de elástico delimitando a área do pula-fio para, como disseram algumas meninas, ver quem consegue pular mais alto sem tocar no fio. A menina de três anos com naturalidade amarra uma corda na árvore e brinca. Nos retiros - local onde se produz farinha, elas brincam por entre as raízes das árvores, com ou sem brinquedo, enquanto os pais labutam.

A fotografia abaixo demonstra um pouco do que se passava ali. Ela foi tomada no terreiro de um dos quilombolas que colaboraram com a pesquisa. No momento do registro, uma de suas netas, encontrava-se imersa no silêncio da terra e do seu brincar, sendo vigiada por outras crianças e animais e está protegida pela sombra das árvores, fração do mundo rural.

@rquivo Brasileiro de Educação, Belo Horizonte, v. 6, n. 14, mai-ago, 2018. 


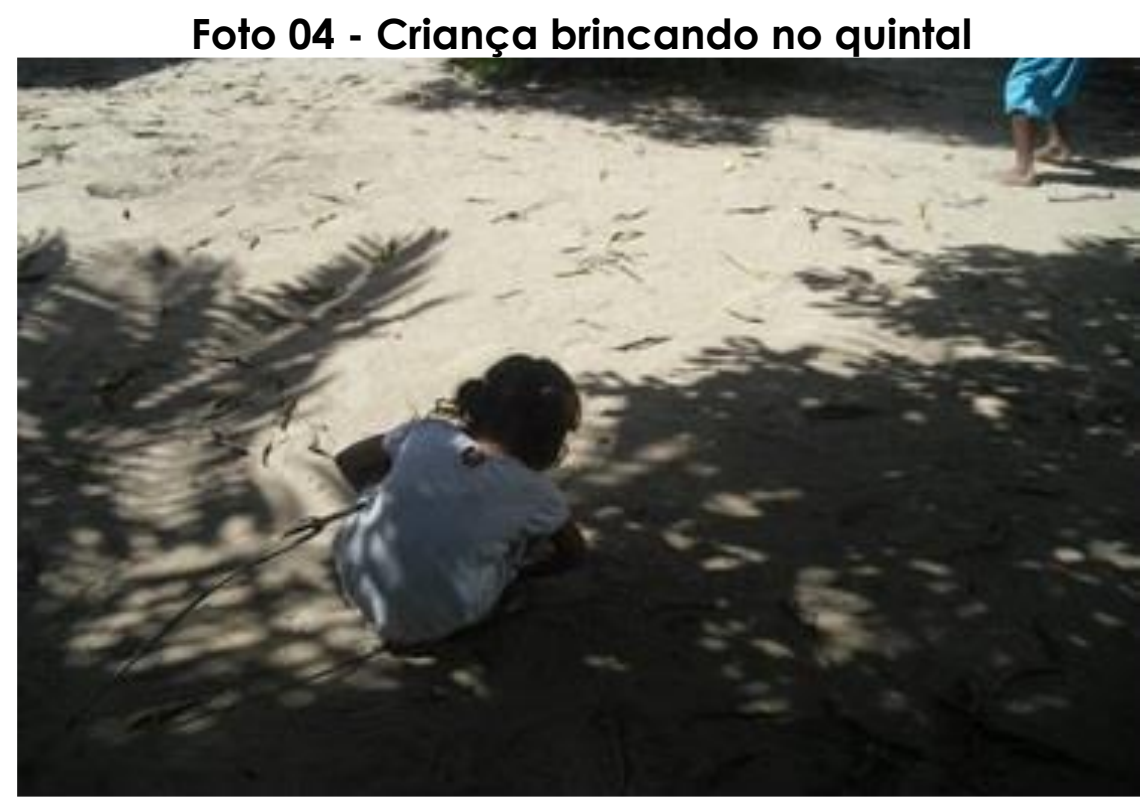

Fonte: Acervo da Pesquisadora.

Passados alguns dias, levei a foto para R.R. (08a). Ela, recebendo-a sorridente, afirmou que o pedaço do galho em sua mão é um pau de brincar e o desenho são coisas na terra, dando visibilidade à construção de suas brincadeiras e instrumentos do brincar.

No caso do contexto de várzea, precisamente, as crianças aprendem a sinergia do que dizem: a gente foi criado n'água, pois as águas e o rio animam o brincar. Constantemente, a canoa ou a rabeta transforma-se em brinquedo que serve para balançar, para passear ou para disputar corridas. Em certa medida, podemos afirmar que o tempo e o tipo da maré, o tempo do brincar, a proximidade ou distância da cabeceira da ponte, o desafio do contato do corpo n'água é que determinam o início e o término de uma ou mais brincadeiras, um jogo. Acompanhei o curso das narrações e ouvi esta: Brinca e toma banho tudo junto quando a maré tá grande (cheia), agora tem o risco do bicho, sucuriju (cobra). O banhar e o brincar em uma prancha, feita pela própria criança, retrata o destemor com as águas, embora, como afirmou o menino, esteja tudo totalmente ordenado pelos

@rquivo Brasileiro de Educação, Belo Horizonte, v. 6, n. 14, mai-ago, 2018. 
pais, por causa dos acidentes, cujo controle exige outros cuidados.

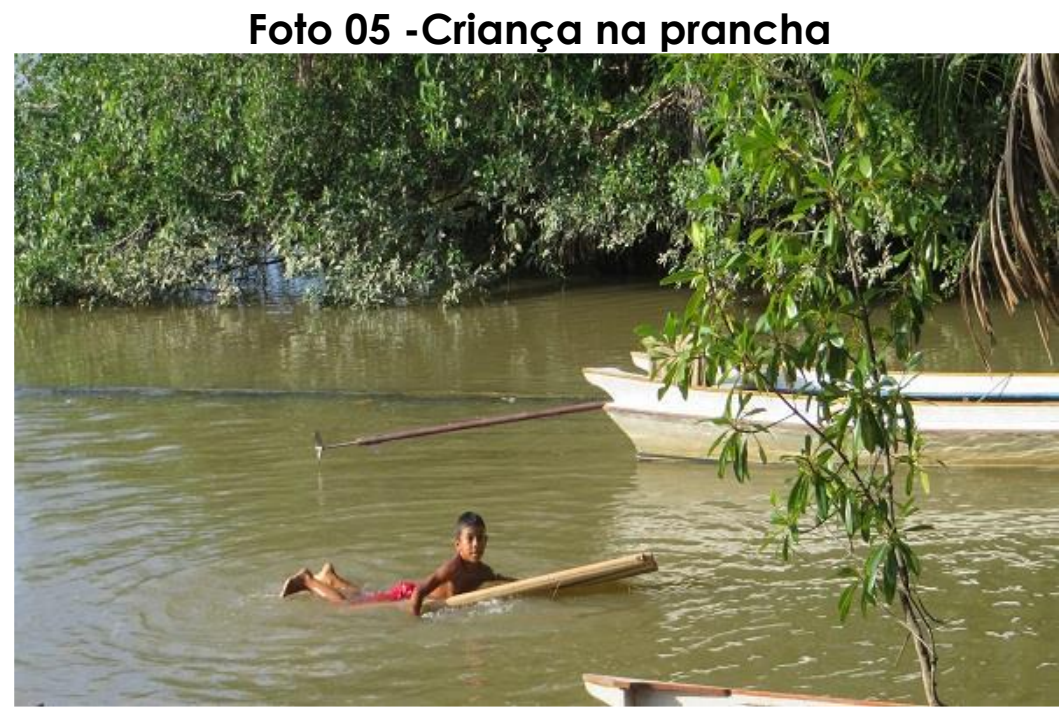

Fonte: Acervo da Pesquisadora

Tais sensações demonstram que as brincadeiras realizadas pelas crianças também traduzem uma cultura camponesa-ribeirinha-quilombola, pois as brincadeiras vividas por crianças e adolescentes se diferenciam das brincadeiras comuns de uma cidade urbana, principalmente pelo contexto e pelas regras.

Além desses brincares, tal como acontece hoje em todos os lugares, as crianças divertem-se com os aparelhos eletrônicos, principalmente quando estão em casa. Mas não exageram, por terem ainda espaços naturais para brincar. Em um dos momentos que eu dialogava informalmente com uma mãe sobre o assunto, as crianças circulavam pelo quintal. Na casa de dona Sabá, em frente da escola, repetidas vezes, observei crianças de idades diferentes andarilhando no terreiro, apanhando frutos (caju, goiaba, araçá) nas árvores, durante a tarde.

Os aprendizados de crianças e de adolescentes tal como eles são vividos nas práticas cotidianas do brincar, situam-se entre as relações

@rquivo Brasileiro de Educação, Belo Horizonte, v. 6, n. 14, mai-ago, 2018. 
escolares e de convivência com adultos, reconhecendo que suas produções culturais muito têm a dizer sobre os saberes locais, sobre processos educativos que transcorrem na vida diária. Seus brincares e o envolvimento delas com as águas e a floresta, situam:

a) Relações com a natureza e com o saber local. Tais sujeitos aprendem os modos de lidar com as águas e com a mata, pois o cotidiano é entrecortado por saberes locais enquanto processos culturalmente construídos. Por exemplo, os brinquedos criados pelas crianças e adultos, como um balanço feito de aro de bicicleta pendurado em uma árvore à beira do rio, evidencia elas serem participantes ativos daquele ambiente de águas. Neste aspecto faz sentido um 'habitarbrincando' das crianças, em que a natureza é percebida como espaço e instrumento. Para uma delas: na canoa se brinca de remar ou, ainda, pela capacidade de reinventar regras do jogo em brincadeiras como as que praticam dentro d'água, ou a inventividade da brincadeira existente no lugar: o formô.

b) Uma interação com as atividades de trabalho. Os pequenos vão incorporando na convivência cotidiana, símbolos e saberes do trabalho e da vida local. Bastante comum, a atividade da apanhação do açaí é uma arte que crianças experimentam brincando e, na maioria das vezes, tornar-se-á uma prática incorporada como a atividade que ajuda a reproduzir a vida individual e a familiar, quando adultos. Nesses termos, ainda que raros e nem sempre visíveis, está sempre presente em tudo uma atividade de uma 'pedagogia patrimonial' e, assim, elas adquirem saberes através de seus envolvimentos e participações em situação de fazeres que os adultos

@rquivo Brasileiro de Educação, Belo Horizonte, v. 6, n. 14, mai-ago, 2018. 
e as próprias crianças são transmissores 'naturais.Por exemplo, as crianças descrevem com riqueza de detalhes como é feita a farinha, a colheita do açaí, o plantio e os usos da mandioca; sabem pilotar rabetas ou conduzir remando as canoas pelos rios; conhecem os instrumentos de trabalho usados pelos pais e a utilidade de cada um.

As crianças e adolescentes participam de uma educação mais funcional e dirigida a práticas do fazer, a do aprendizado do saber local. Praticando, dominam tanto o andar de bicicleta como os sentidos do trabalho, aprendem discriminar os tipos de embarcações e identificar a maré cheia da seca; aprendem a gostar de andar descalços nos terreiros, e assim por diante. Elas, espontaneamente ou convocadas pelos mais velhos para ajudarem em alguma coisa, observam como se faz, imitam e, assim, 'vão aprendendo'. Aprende-se por observação direta e através da repetição de gestos e de atos. Mesmo quando há uma intencionalidade de ensinar alguma coisa, este momento se passa de forma tão corriqueira no contexto de uma atividade, que a sua 'dimensão pedagógica' parece ficar quase invisível.

Em suma, as crianças estão imersas por um repertório simbólico e lúdico próprio que nos incitam a pensar a infância a partir da realidade que elas estão envolvidas e como elas se colocam diante dos sistemas socioculturais e territoriais. Elas possuem uma vida dividida entre a convivência com a família, o convívio com a escola e o brincar. Tais convívios podem ser visualizados na vizinhança, na igreja, na reunião de grupos brincantes, nas conversas por entre as pontes das casas e os trapiches ou nos arredores de árvores. No caso, além da escola, as crianças ribeirinhas e quilombolas que participaram da pesquisa se socializam

@rquivo Brasileiro de Educação, Belo Horizonte, v. 6, n. 14, mai-ago, 2018. 
brincando em casa, no rio ou no quintal e, também, ajudando seus responsáveis no trabalho diário, especialmente na apanhação do açaí.

As atuais e as antigas abordagens sobre desenvolvimento e de formação das crianças sinalizam que o brincar auxilia na construção de esquemas mentais e simbólicos. Por meio da brincadeira, elas se expressam, cooperam e representam um momento real de uma dada situação de pertencimento de uma realidade. Nesse sentido, "O brincar da criança é o eixo central de sua experiência pessoal, familiar (entre irmãos) e grupal (dentro de grupos de idade e de grupos de interesse) de vida. Ele equivale à obsessiva importância que damos ao trabalhar nas culturas dos adultos" (BRANDÃO, 2015, p.113, grifos do autor).

Assim, de muitos modos uma variada dimensão socializadora está sempre presente. Os locais da pura brincadeira a cada dia rivalizam com a casa, a família e a escola, e as complementam como momentos e situações de um aprendizado que recobre as três dimensões interligadas, isto é, brincando também se aprende práticas do fazer, éticas do agir e lógicas do pensar (BRANDÃO, 2015).

\section{ALGUNS PONTOS PARA CONTINUAR A CONVERSA!}

Foi possível perceber que há uma imbricação do mundo das crianças com a natureza na constituição do brincar, do ajudar nas tarefas laborais, do estudar, ou seja, interagem com o fluxo cotidiano da comunidade. Elas transitam por costumes, jeitos, tempos, cultura(s) que marcam o viver ali.

O cotidiano de águas é parte constitutiva e imprescindível na construção do gênero de vida do sujeito rural-ribeirinho-quilombola na região tocantina, de modo geral. A água possui usos diversificados,

\footnotetext{
@rquivo Brasileiro de Educação, Belo Horizonte, v. 6, n. 14, mai-ago, 2018.
} 
conformam situações de conflitos e de alteridades, manifesta-se como um signo cultural e funciona como a 'rua' no trânsito de pessoas e embarcações. Dessa forma, espraiada na linguagem cabocla, por costumes e crendices, por saberes e sociabilidades, por dimensões simbólicas de trocas e ações comunitárias de grupo camponês entre outras formas da prática social; a tradição local e quilombola/ribeirinha é produzida e vivificada pelo verter das águas, reinventa-se no regime amazoniágua, que com suas enchentes e vazantes faz pulsar a vida social, a economia local e o ciclo produtivo.

No caso, as relações estabelecidas com os saberes das águas e com todo um conjunto de outros saberes, remete ao que nos ensinou Lévi-Strauss (1976) em suas formulações acerca de uma ciência primeira, próxima de uma lógica do sensível, porque tomando a lógica dos interlocutores da pesquisa, criam-se e se recriam possibilidades em sintonia com os recursos, ou seja, há uma atitude prospectiva de reinvenção dos conteúdos culturais existentes no lugar, exemplos são os diversos brincares nos cursos d'água: corrida na água; remar e passear na canoa; pular de um aro no rio; tomar banho brincando de pular; natação; consequência de uma curiosidade que os move e que os coloca na condição de 'atravessados' à natureza, ao mesmo tempo que seus valores do conviver, suas tradições e suas simbologias amazônicas convertem-se em processos educativos no ordinário da vida.

Tal interação humano-águas num cotidiano que se faz e se refaz denota uma singularidade rural-ribeirinha-quilombola, de significativa valorização dos sujeitos do campo como espaço de vida, de cultura e de trabalho. E, esse conjunto de saberes das águas sinalizam ou ratificam uma importante produção cultural viva que muito pode contribuir com reflexões

@rquivo Brasileiro de Educação, Belo Horizonte, v. 6, n. 14, mai-ago, 2018. 
sobre a nossa condição planetária, de respeito e valorização da pessoa humana; bem como podem ser o ponto de partida e de chegada para pensarmos outras formas de pedagogia escolar em comunidades rurais da Amazônia paraense.

Através de um complexo de relações que partem de dentro das casas, atravessam a floresta e o rio, passam pelas roças e os retiros, e chegam até a escola processa-se todo um conjunto de saberes aprendidos de forma espontânea ou motivada. Saberes e teias de saberes que contribuem para que crianças, adolescentes e adultos quilombolas/ribeirinhos se conectem com a dinâmica sociocultural e educativa do lugar. Por essas experiências interconectadas, crianças e adolescentes interagem com coletivos pedagógicos dentro e fora da escola. Eles misturam tempos geracionais proporcionando uma transmissão do saber a partir da unidade familiar.

Assim, os momentos de expressões dos corpos e das mentes do brincar dos pequenos conectam-se intensamente com outras dimensões e situações do aprendizado da cultura camponesa; já que com tais ações as crianças lidam com e criam em sua sociedade as estratégias e os 'jeitos' de serem sujeitos infantis no relacionamento familiar e no território. Pelo brincar as crianças aprendem a conviver, reunindo-se em lugares específicos para tanto e construindo coletivamente formas de apreender e formas de perceber o mundo. Significa pensar o cotidiano enquanto redes de fazeressaberes construídos pelos sujeitos no cotidiano da vida. Em outras palavras, deixemos as histórias das crianças serem contadas por elas mesmas e, quem sabe, por meio do saber-fazer delas estaremos ensaiando recuperar uma possível dignidade perdida ou, quem sabe, tais histórias possam formar e humanizar.

@rquivo Brasileiro de Educação, Belo Horizonte, v. 6, n. 14, mai-ago, 2018. 
Por último, mas como algo necessário, as pontuações aqui trazidas são espiares sobre o aprendizado infantil, baseado em um olhar inicial e em aprofundamento. Reconheço que aprofundar tais temas exige investigá-los durante um tempo que envolva todo um ciclo anual da vida local e do calendário escolar. E exige ainda um adentrar, ciclo a ciclo, pela vida e os vários tempos-espaços cotidianos de que participam. Daí um texto em construção!

\section{REFERÊNCIAS}

ALMEIDA, Alfredo Wagner Berno de; FARIAS JUNIOR, Emmanuel de Almeida (Org.). Povos e comunidades tradicionais: nova cartografia social. Manaus: UEA, 2013.

ANDRADE, Simei Santos; PACHECO, Tatiana do Socorro Corrêa. Infâncias e crianças ribeirinhas da Amazônia marajoara: linguagens e práticas culturais. Revista @rquivo Brasileiro de Educação, Belo Horizonte, v. 4, n. 9, p. 104-116. set./dez. 2016.

BRANDÃO, Carlos Rodrigues. Olhar o mundo e ver a criança: ideias e imagens sobre ciclos de vida e círculos de cultura. Crítica Educativa, Sorocaba, v. 1, n. 1, p. 108-132, jan./jun. 2015.

BRANDÃO, Carlos Rodrigues; BORGES, Maristela Corrêa. Criar com o outro: o educador do diálogo. Revista Educação Popular, Uberlândia, v. 7, p.12-25, jan./dez. 2008.

BENJAMIN, Walter. Reflexões: a criança, o brinquedo, a educação. Tradução de Marcus Vinicius Mazzari. São Paulo: Summus, 1984.

BROUGÈRE, Gilles. Brinquedo e cultura. 3 ed. São Paulo: Cortez, 2000.

CASTRO, Edna. Território, biodiversidade e saberes de populações tradicionais. In: DIEGUES, Antonio Carlos San'Ana. (Org.). Etnoconservação: novos rumos para a conservação da natureza. São Paulo: Hucitec/NupaubUSP, 2000. p.165-182.

CASTRO, Edna. Território, biodiversidade e saberes de populações

@rquivo Brasileiro de Educação, Belo Horizonte, v. 6, n. 14, mai-ago, 2018. 
tradicionais. In: CASTRO, Edna; PINTON, Florence. (Org.). Faces do trópico úmido: conceitos e novas questões sobre desenvolvimento e meio ambiente. Belém: CEJUP; UFPA-NAEA, 1997. p. 221-242.

CUNHA, Euclides da. À margem da história. São Paulo: Martins Fontes, 1999.

FERNANDES, Florestan. As 'trocinhas' do Bom Retiro. In: FERNANDES, Florestan. Folclore e mudança social na cidade de São Paulo. 2. ed. Rio de Janeiro: Vozes, 1979. p. 153-258.

GUSMÃO, Neusa Maria Mendes de. Olhar viajante: antropologia, criança e aprendizagem. Revista Pro-Posições, Campinas, v. 23, n. 2 (68), p. 161-178, maio/ago. 2012.

GUSMÃO, Neusa Maria Mendes de. A questão política das chamadas "Terras de Preto". In: LEITE, Ilka Boaventura. Terras e territórios de negros no Brasil. Florianópolis: Imprensa Universitária da UFSC, 1991. p. 25-37.

GEERTZ, Clifford. A interpretação das culturas. Rio de Janeiro: Guanabara, 1989.

KRAMER, S. A infância e sua singularidade. In: BEAUCHAMP, J. et al. Ensino fundamental de nove anos: orientações para a inclusão da criança de seis anos de idade. Brasília: Ministério da Educação, Secretaria de Educação Básica, 2007, p. 13-24.

LÉVI-STRAUSS, C. O pensamento selvagem. Tradução de Maria Celeste da Costa e Souza e Almir de Oliveira Aguiar. São Paulo: Companhia Editora Nacional, 1976.

LOUREIRO, João de Jesus Paes. Cultura Amazônica: uma poética do imaginário. 4. ed. Belém: Cultural Brasil, 2015.

MACHADO, J. Nosso Folclore: panorama do folclore amazônico. Abaetetuba: Alquimia, 2008.

MACHADO, J. Glossário abaeteense: palavras e expressões do linguajar regional. Abaetetuba: Alquimia, 2005.

MARTINS, José de Souza. Fronteira: a degradação do Outro nos confins do humano. $2^{\mathrm{a}} \mathrm{ed}$. São Paulo: Ed. Contexto, 2014.

MAUSS, Marcel. 2003. Ensaio sobre a dádiva: forma e razão da troca nas

@rquivo Brasileiro de Educação, Belo Horizonte, v. 6, n. 14, mai-ago, 2018. 
sociedades arcaicas. Tradução de Paulo Neves. São Paulo: Cosac Naify, 2013.

MAUÉS, Raymundo Heraldo. Uma outra "invenção" da Amazônia: religiões, histórias, identidades. Belém: CEJUP, 1999.

NAHUM, João Santos; SANTOS, Cleison Bastos dos. Impactos socioambientais da dendeicultura em comunidades tradicionais na Amazônia paraense.

Revista de geografia agrária, Boa Vista, v. 6, n. 12, p. 63-80, 2013.

OLIVEIRA, Adolfo da Costa; OLIVEIRA, Ivanilde Apoluceno de. Cartografias ribeirinhas: saberes e representações sobre práticas sociais cotidianas de alfabetizandos amazônidas. 2. ed. Belém: EDUEPA, 2008.

POJO, Eliana Campos. Gapuiar de saberes e de processos educativos e identitários na comunidade do Rio Baixo Itacuruçá, Abaetetuba - PA. 2017. 243 f. Tese (Doutorado em Ciências Sociais) - Instituto de Filosofia e Ciências Humanas, Universidade Estadual de Campinas, Campinas, 2017.

REZENDE, Roberto Sanches. Camponeses da bacia do rio Tejo: economia, política e afeto na Amazônia. 2016. 265 f. Tese (Doutorado em Antropologia Social) Instituto de Filosofia e Ciências Humanas, Universidade Estadual de Campinas, Campinas, 2016.

SOUZA, Angela Fagna Gomes de. Ciclos de vida nos lugares das águas:as ilhas do rio São Francisco em Pirapora/MG. In: OLIVEIRA, Claudia Luz de; COSTA, João Batista de Almeida. (Org.). Cerrado, Gerais, Sertão: comunidades tradicionais nos sertões roseanos. São Paulo: Intermeios; Belo Horizonte: FAMING; Montes Claros: Unimontes, 2012. p. 63-75. 